\title{
Article \\ The Ketogenic Diet Improves Gut-Brain Axis in a Rat Model of Irritable Bowel Syndrome: Impact on 5-HT and BDNF Systems
}

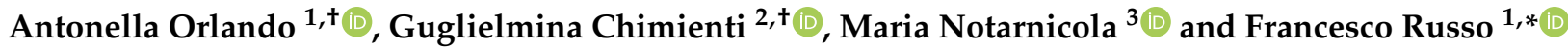 \\ 1 Laboratory of Nutritional Pathophysiology, National Institute of Gastroenterology "S. de Bellis", \\ IRCCS Research Hospital, 70013 Castellana Grotte, Italy; antonella.orlando@irccsdebellis.it \\ 2 Department of Biosciences, Biotechnologies and Biopharmaceutics, University of Bari Aldo Moro, \\ Via Orabona 4, 70125 Bari, Italy; guglielminaalessandra.chimienti@uniba.it \\ 3 Laboratory of Nutritional Biochemistry, National Institute of Gastroenterology "S. de Bellis", \\ IRCCS Research Hospital, 70013 Castellana Grotte, Italy; maria.notarnicola@irccsdebellis.it \\ * Correspondence: francesco.russo@irccsdebellis.it; Tel.: +39-080-4994315 \\ + These authors contributed equally to this work.
}

Citation: Orlando, A.; Chimienti, G.; Notarnicola, M.; Russo, F. The Ketogenic Diet Improves Gut-Brain Axis in a Rat Model of Irritable Bowel Syndrome: Impact on 5-HT and BDNF Systems. Int. J. Mol. Sci. 2022, 23, 1098. https://doi.org/10.3390/ ijms 23031098

Academic Editor: Simon McArthur

Received: 21 December 2021

Accepted: 17 January 2022

Published: 20 January 2022

Publisher's Note: MDPI stays neutral with regard to jurisdictional claims in published maps and institutional affiliations.

Copyright: (c) 2022 by the authors. Licensee MDPI, Basel, Switzerland. This article is an open access article distributed under the terms and conditions of the Creative Commons Attribution (CC BY) license (https:// creativecommons.org/licenses/by/ $4.0 /)$.

\begin{abstract}
Altered gut-brain communication can contribute to intestinal dysfunctions in the intestinal bowel syndrome. The neuroprotective high-fat, adequate-protein, low-carbohydrate ketogenic diet (KD) modulates the levels of different neurotransmitters and neurotrophins. The aim was to evaluate the effects of $\mathrm{KD}$ on levels of 5-HT, the receptors $5-\mathrm{HT}_{3 \mathrm{~B}}$ and $5-\mathrm{HT}_{4}$, the $5-\mathrm{HT}$ transporter SERT, the neurotrophin BDNF, and its receptor TrkB in the colon and brain of a rat model of irritable bowel syndrome (IBS). Samples from Wistar rats exposed to maternal deprivation as newborns and then fed with a standard diet (IBS-Std) or KD (IBS-KD) for ten weeks were analyzed. As controls, unexposed rats (Ctrl-Std and Ctrl-KD) were studied. IBS-Std rats had a disordered enteric serotoninergic signaling shown by increased mucosal 5-HT content and reduced SERT, 5- $\mathrm{HT}_{3 \mathrm{~B}}$, and $5-\mathrm{HT}_{4}$ levels compared to controls. In the brain, these animals showed up-regulation of the BDNF receptor TrkB as a counteracting response to the stress-induced reduction of the neurotrophin. KD showed a dual effect in improving the altered 5-HT and BDNF systems. It down-regulated the increased mucosal 5-HT without affecting transporter and receptor levels. KD improved brain BDNF levels and established negative feedback, leading to a compensatory downregulation of TrkB to maintain a physiological steady state.
\end{abstract}

Keywords: 5-HT; animal model; BDNF; irritable bowel syndrome; ketogenic diet

\section{Introduction}

Irritable Bowel Syndrome (IBS) is a gastrointestinal (GI) functional disorder characterized by GI motor and sensory dysfunctions in the absence of structural abnormalities; it is highly prevalent, chronic, recurrent, and remitting in the population worldwide. Mainly for clinical purposes, IBS is categorized into four different subtypes according to the bowel habits of patients: IBS-D (diarrhea prevalent), IBS-C (constipation prevalent), IBS-M (mixed form), and IBS-U (unspecified) [1].

Chronic pain, anxiety, and depression frequently overlap with IBS [2]. The gut-brain axis is involved in the perception and regulation of visceral sensitivity, linking peripheral GI functions with the sensitive and cognitive centers in the brain [3]. Therefore, altered communication between the two systems can contribute to intestinal dysfunctions (e.g., the induction of visceral pain, disturbed GI motility, the onset of leaky gut, and deregulated entero-endocrine signaling) [4].

As signaling transducers, the neurotransmitter serotonin (5-HT) and the neurotrophin brain-derived neurotrophic factor (BDNF) have been proved to expand their functions outside the central nervous system (CNS) and mediate the signaling with the intestine $[5,6]$. 
In the CNS, 5-HT controls mood, sleep, and appetite, whereas it regulates motility, secretion, sensation, inflammation, and the barrier function in the gut. Tryptophan hydroxylases $\mathrm{TpH} 1$ and $\mathrm{TpH} 2$ synthesize $5-\mathrm{HT}$ in the enterochromaffin cells (ECs) in the intestine and neurons, respectively, composing about $95 \%$ of the neurotransmitters concentrated in the gut [7]. The serotonergic signaling relies on several selective receptor subtypes and is terminated via the 5-HT reuptake transporter (SERT) [8].

The pathophysiological role of 5-HT and SERT, together with 5-HT 3 and 5-HT 4 receptors, has been widely highlighted in IBS. These two receptors mediate serotonin-induced signaling in the gut [9] and are also expressed in the brain [10]. The mucosal release of 5-HT stimulates internal sensory neurons (most likely through $5-\mathrm{HT}_{4}$ receptors) and external sensory neurons (through 5- $\mathrm{HT}_{3}$ receptors) [11]. Previous studies have shown that both $5-\mathrm{HT}_{3}$ and $5-\mathrm{HT}_{4}$ receptor agonists can stimulate GI motility [12]. Like the 5- $\mathrm{HT}_{3}$ receptor, the $5-\mathrm{HT}_{4}$ receptor seems to exert multifaceted roles, mainly mediating the relaxation and contraction of circular smooth muscle [13,14].

These molecules have become attractive targets for pharmacological treatments to reduce or promote gut motility, specifically for the IBS-D and IBS-C subtypes [15]. Furthermore, diets fortified with natural compounds (such as berberine or resveratrol) have been recently proposed as a therapeutic intervention to reduce serotonin signaling in IBS patients [16-18] and animal models [3].

The neurotrophin BDNF is involved in the development and regeneration of several neuronal populations in the CNS [19], so decreased neuroplasticity can be associated with the psychological comorbidities related to IBS [20]. BDNF is also an essential neurotrophic factor in the GI tract, where it is synthesized by several cell types, such as enterocytes, neurons, and glial cells [21]. Beyond its neuroprotective and neuroplastic roles, it controls visceral sensation, motility, and intestinal barrier functions [22,23]; thus, along with its cognate tropomyosin-related kinase receptor B (TrkB), it plays a role in hypersensitivity conditions via facilitating sensory nerve growth [24] and its interaction with enteroglial cells [25], although with sex-linked differences [26]. Some studies have been performed in rat models of IBS, showing the effectiveness of the BDNF blockage signaling as a possible therapeutic option for visceral hypersensitivity $[27,28]$.

Overall, several findings strongly support the potential beneficial role of a nutritional approach to IBS management [29]. In this context, different data suggest that the high-fat, low-carbohydrate, and adequate-protein ketogenic diet (KD) is not only neuroprotective [30], probably through its effects on mitochondria function, cellular energetics, inflammation, and pain thresholds [31], but it also can modulate the circulating levels of intestinal microbiota and neurotransmitters [32].

On this basis, the present study aimed to evaluate the effects of KD on the levels of 5-HT and BDNF systems in Wistar rats exposed to maternal deprivation (MD) as newborn, as early life stress can induce IBS in adulthood [33].

Considering the importance of the gut-brain interconnections, we evaluated the levels of 5-HT, of the receptors $5-\mathrm{HT}_{3 \mathrm{~B}}$ and $5-\mathrm{HT}_{4}$ and the 5- $\mathrm{HT}$ transporter SERT, of the neurotrophin BDNF and its cognate receptor TrkB in colon and brain samples of MD exposed rats fed with a standard diet (IBS-Std) or KD (IBS-KD) for ten weeks. In addition, as control groups, unexposed rats fed with a standard diet (Ctrl-Std) or KD (Ctrl-KD) were also studied.

\section{Results}

\subsection{Serotonin Levels}

Serotonin levels were determined by ELISA in colon and brain tissue samples from rats belonging to the four experimental groups. In colon samples, the levels of 5-HT were significantly $(p=0.0001) 3.8$-fold higher in IBS-Std rats $(6.06 \pm 0.38 \mathrm{ng} / \mathrm{mg}$ prot.) compared to both Ctrl-Std (1.58 $\pm 0.68 \mathrm{ng} / \mathrm{mg}$ prot.) and Ctrl-KD ones (1.62 $\pm 0.47 \mathrm{ng} / \mathrm{mg}$ prot.). In the group of IBS rats given KD, the diet appeared to have a neutralizing action as serotonin levels were 1.7 times lower than in the IBS-Std group $(p=0.0134 ; 3.56 \pm 0.26 \mathrm{ng} / \mathrm{mg}$ prot. 
vs. $6.06 \pm 0.38 \mathrm{ng} / \mathrm{mg}$ prot.) (Figure 1, panel A). Conversely, no significant differences in 5-HT levels were found in brain samples among the four groups (Figure 1, panel B).

A

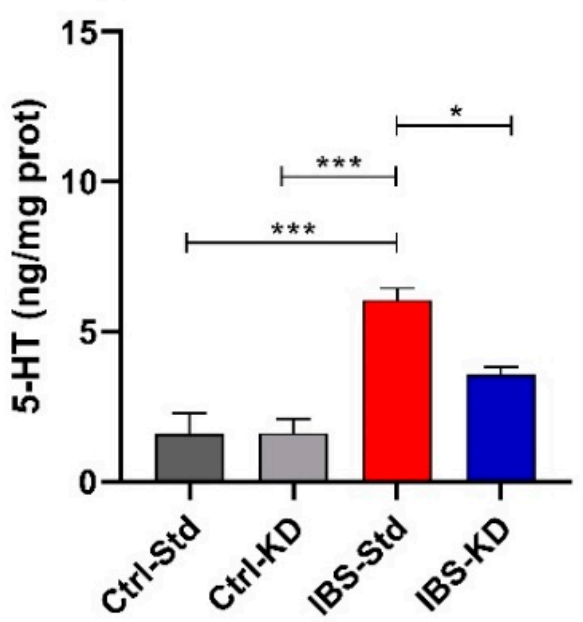

B

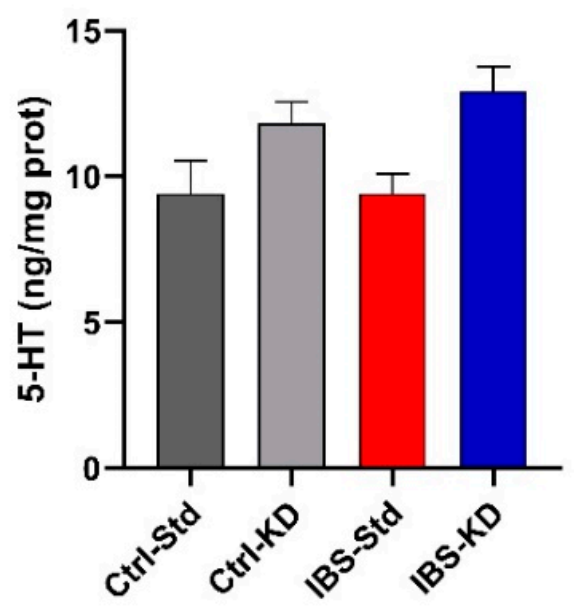

Figure 1. The 5-HT levels are expressed as $\mathrm{ng} / \mathrm{mg}$ protein in the colon (Panel A) and brain (Panel B) samples of Ctrl-Std, Ctrl-KD, IBS-Std, and IBS-KD rats, with each group consisting of four rats. Data were analyzed by Kruskal-Wallis analysis of variance and Dunn's Multiple Comparison Test $\left({ }^{*} p<0.05 ;{ }^{* * *} p<0.001\right)$.

\subsection{5-HT System}

The serotonin system was evaluated by Western blot analysis by determining the content of $5-\mathrm{HT}_{3 \mathrm{~B}}, 5-\mathrm{HT}_{4}$, and SERT proteins expressed as relative intensity (mean $\pm \mathrm{SEM}$ ) of the immunoreactive band in colon and brain tissue samples of Ctrl-Std, Ctrl-KD, IBS-Std, and IBS-KD rats.

As for 5- $\mathrm{HT}_{3 \mathrm{~B}}$ in the colon, no significant differences were observed among the groups of rats (Figure 2, panel A). On the contrary, $5-\mathrm{HT}_{4}$ protein showed a significant $(p=0.0478)$ six-fold decrease in IBS-Std rats compared to Ctrl-Std ones (0.53 \pm 0.21 vs. $3.11 \pm 0.91)$ (Figure 2, panel B). As for the levels of SERT protein, the IBS-Std group showed significantly $(p=0.049)$ reduced (3.6-fold) in comparison with Ctrl-Std rats $(0.63 \pm 0.20$ vs. $2.27 \pm 0.56)$ (Figure 2, panel C).

A
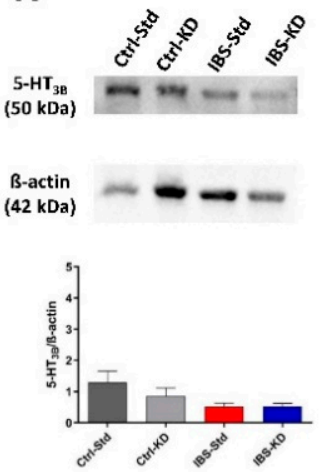

B
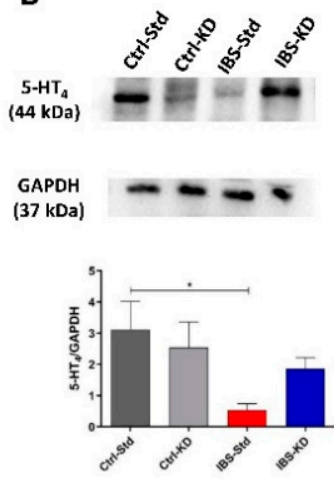

C
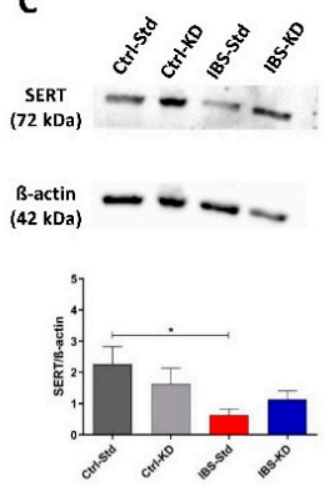

Figure 2. Western blot analysis of 5- $\mathrm{HT}_{3 \mathrm{~B}}$ (Panel A), 5- $\mathrm{HT}_{4}$ (Panel B), and SERT (Panel C) proteins in colon samples of Ctrl-Std, Ctrl-KD, IBS-Std, and IBS-KD rats, with each group consisting of four rats. Data were analyzed by Kruskal-Wallis analysis of variance and Dunn's Multiple Comparison Test $\left({ }^{*} p<0.05\right)$. 
As reported in Figure 3, the content of 5- $\mathrm{HT}_{3 \mathrm{~B}}, 5-\mathrm{HT}_{4}$, and SERT proteins in brain samples of Ctrl-Std, Ctrl-KD, IBS-Std, and IBS-KD rats were not significantly different among the four experimental groups of rats (Figure 3, panel A-C).

A
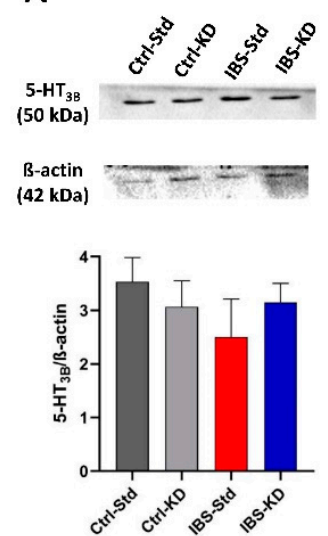

B
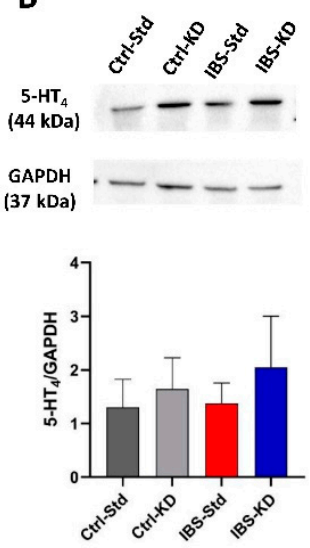

C
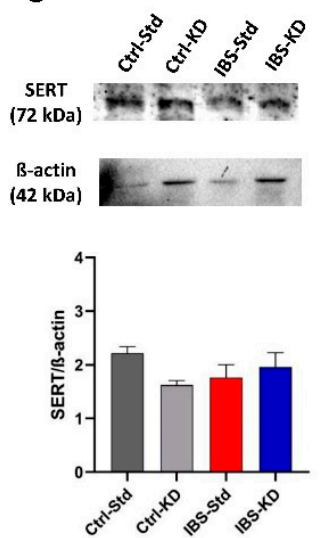

Figure 3. Western blot analysis of 5- $\mathrm{HT}_{3 \mathrm{~B}}$ (Panel A), 5- $\mathrm{HT}_{4}$ (Panel B), and SERT (Panel C) proteins in brain samples of Ctrl-Std, Ctrl-KD, IBS-Std, and IBS-KD rats, with each group consisting of four rats. Data were analyzed by Kruskal-Wallis analysis of variance and Dunn's Multiple Comparison Test.

\subsection{BDNF System}

The BDNF and TrkB protein levels were evaluated by Western blot analysis in colon and brain samples from the four experimental rat groups and expressed as the immunoreactive bands' relative intensity (mean \pm SEM). In both the tissues, the main BDNF immunoreactive product was a $28 \mathrm{kDa}$ band, corresponding to the stable homodimer formed by the mBDNF form.

No significant differences were found in BDNF dimer levels among rat colon samples (Figure 4). Western blot analysis could not highlight any TrkB immunoreactive band in colon samples (data not shown).

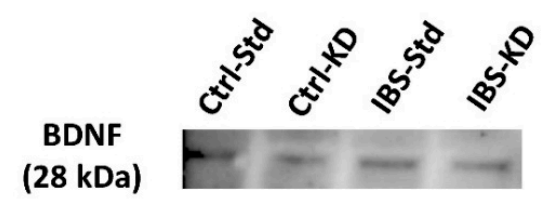

\section{B-actin (42 kDa)}

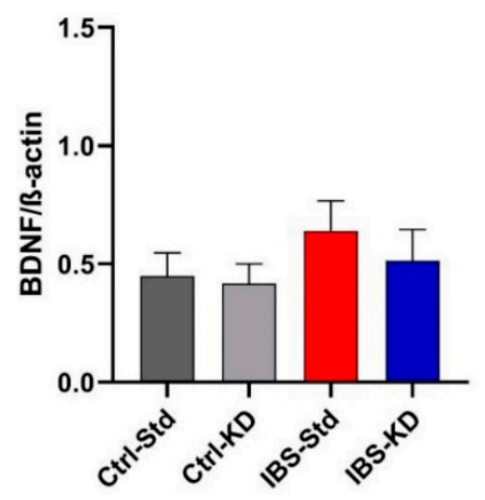

Figure 4. Western blot analysis of BDNF protein in colon samples of Ctrl-Std, Ctrl-KD, IBS-Std, and IBS-KD rats, with each group consisting of four rats. Data were analyzed by Kruskal-Wallis analysis of variance and Dunn's Multiple Comparison Test. 
In the brain, the levels of the BDNF dimer were different among the four groups of rats, with the minimum value shown by IBS rats fed a standard diet (Figure 5, panel A). The post-test showed the significance of the difference for comparing IBS rats, with the IBS-KD showing a 2.6-fold increased value compared to IBS-Std ( $p=0.0354 ; 0.39 \pm 0.10 \mathrm{vs}$. $1.00 \pm 0.21$ ). The effects of MD and feeding with KD on the BDNF cognate TrkB receptor levels were evaluated (Figure 5, panel B). A difference was observed in the levels of the TrkB immunoreactive band among the groups, with the statistical significance between Ctrl-Std and IBS-Std, the latter showing a 2.2-fold increased value $(p=0.0417 ; 0.33 \pm 0.09$ vs. $0.74 \pm 0.12)$.

\section{A}

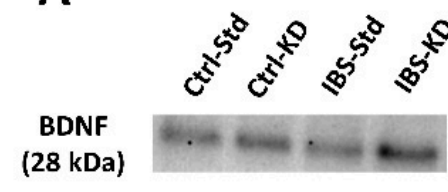

$$
\text { ß-actin }
$$$$
\text { (42 kDa) }
$$

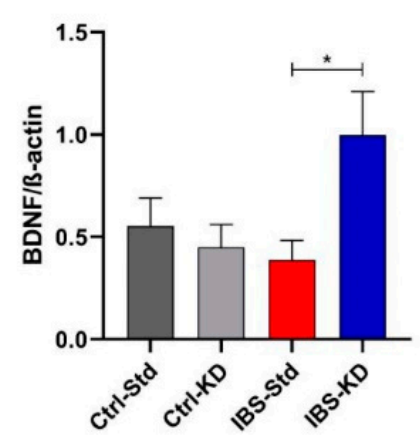

B
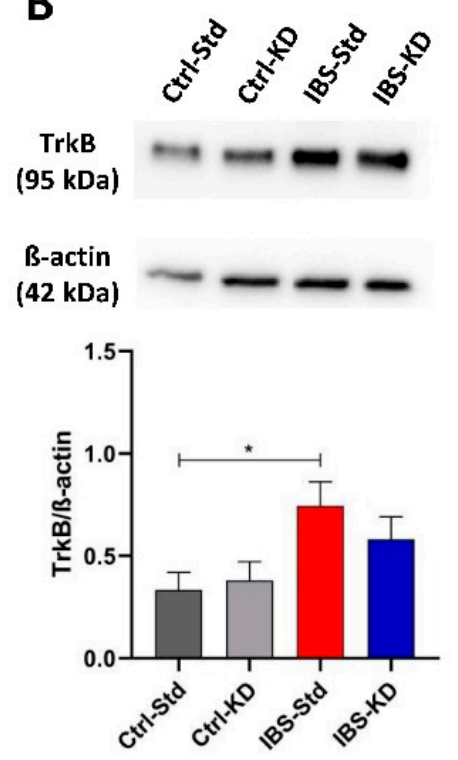

Figure 5. Western blot analysis of BDNF (Panel A) and TrkB (Panel B) proteins in brain samples of Ctrl-Std, Ctrl-KD, IBS-Std, and IBS-KD rats, each group consisting of four rats. Data were analyzed by Kruskal-Wallis analysis of variance and Dunn's Multiple Comparison Test $\left({ }^{*} p<0.05\right)$.

\section{Discussion}

Recent evidence suggests that changing IBS patients' eating habits could be proposed as a sustainable and lasting optional approach to drug treatment to ameliorate their symptom profile [29]. Additionally, it is now accepted how altered communication between the gut and the brain can contribute to intestinal and psychological dysfunctions observed in IBS [4]. In this framework, and derived mainly from preliminary results in animal studies [34-36], KD could show some interesting therapeutic potentiality.

The animal model used in this research was based on MD in the newborn Wistar rats as a trigger for mimicking IBS in adulthood and the administration of KD characterized by a low-carbohydrate content and high-fat levels. This kind of diet induces a metabolic shift to the use of ketones as a source of energy for cells. It is also depicted as a carbohydraterestricted diet with a 4:1 ratio of fats to proteins and carbohydrates [37,38].

On this basis, the present study aimed to evaluate whether feeding with KD could counteract the derangement of the gut-brain interconnections in IBS. For this purpose, protein levels of 5-HT, 5-HT3B, and 5-HT4 receptors, the transporter SERT, of the neurotrophin BDNF and its receptor TrkB were evaluated in colon and brain samples of rats that had been exposed to MD for two weeks after birth and then fed with KD for a further ten weeks [29,33].

Results from the present study suggested that two weeks of MD induced abnormalities in the gut-brain axis in adulthood, particularly alterations of 5-HT and BDNF systems in the colon and the brain of the exposed rats. The induced dysfunctions were of different degrees in the two tissues. As reported by Yu et al. [3], a combination of several chronic 
and acute stressors leads to significant alterations of 5-HT-dependent signaling in both the periphery and in the CNS of the exposed rats. The design of the present study comprised a less severe treatment, consisting only of maternal deprivation. However, the observed changes reached statistical significance depending on the organ where the molecules are most represented or mainly exert their functions since 5-HT significantly changed only in the gut where it is wholly localized [7], while BDNF changed in the brain. In fact, BDNF, although abundant in the periphery [21], exerts its primary function as a neurotrophin on neuronal populations in the CNS [19].

Overall, these results indicate a relationship between the extent of stress and the induced abnormalities of the gut-brain interconnections, and it is interesting to note that the dysfunctions were opposite in their consequences. In the colon of IBS-Std rats, 5-HT appeared to increase relative to controls, while BDNF decreased in the brain. The significantly increased mucosal 5-HT content in IBS-Std rats was associated with reduced SERT, $5-\mathrm{HT}_{3 \mathrm{~B}}$, and $5-\mathrm{HT}_{4}$ receptors compared to controls. This evidence well fits with the hypothesis formulated by Camilleri et al. [39] to explain the disordered enteric serotoninergic signaling in IBS, since it appears that a failure to inactivate the increased serotonin leads to a down-regulation of the receptors.

As concerns the neurotrophin, no firm conclusion can be drawn from the literature regarding the levels of the BDNF protein both in the colon of IBS patients and in animal models. Immunohistochemical data suggested increased BDNF mucosal levels in IBS patients [24], whereas Western blot analysis did not show significant differences between patients and controls [26]. From our data on rats, only a slight increase in BDNF protein in the colon could be inferred in the setting of MD-induced IBS. Other authors have demonstrated through Western blot analysis the significantly increased colon BDNF, however, in a rat model of IBS receiving chronic acute combining stress [3] and in a mouse model of IBD [40]. In our colon samples, we could not identify a TrkB immunoreactive band, agreeing with the reported deficient expression levels of the protein in the colon [41].

The present study showed a concerted response to MD of BDNF and its receptor in the brain. In IBS rats fed a standard diet, levels of the neurotrophin were the lowest, whereas those of TrkB were the highest compared to the other experimental groups. It can be assumed that an up-regulation of the receptor was a counteracting response to the stress-induced reduction of brain BDNF, as already demonstrated in another model of a stressed animal [42].

The KD-associated reduction in carbohydrates forces the body to primarily use fat as fuel by miming the fasting state. It is used as a dietary intervention to treat several neurological and psychiatric disorders [30], although its role in treating other diseases such as nonalcoholic fatty liver disease [43], or even as an adjuvant treatment for cancer, is now emerging [44]. The beneficial effects of the intervention appear to rely on, among the other proposed mechanisms [31,32], the ability of KD to decrease biogenic amines such as 5-HT [45]. Furthermore, it has been shown that circulating levels of BDNF are influenced by calorie restriction in obese subjects [46], and more specifically by dietary PUFA, with a significant role also played by genetics, as shown in celiac patients [47]. Additionally, circulating and brain BDNF levels have been shown to increase with $\beta$ oxidation of free fatty acids, along with the short-chain fatty acid $\beta$-hydroxybutyrate that is produced in the setting of carbohydrate restriction, fasting, or hypoglycemia, at least in subjects attempting prolonged and exhaustive physical exercise [48,49]. Data concerning the effect of dietary fat on the levels of BDNF in the gut are scarce; it has only recently been demonstrated that a high-fat diet induces a reduction of the expression of BDNF in duodenal neurons [50].

As recently published elsewhere by our group, we have already demonstrated the effectiveness of KD in ameliorating intestinal membrane functions and gut mitochondrial biogenesis in the animal model of IBS, along with the inflammatory status $[35,36]$. 
This study showed a dual effect of KD in improving the altered 5-HT and BDNF systems. Dietary intervention was able to down-regulate the increased 5-HT observed in the colon of IBS-Std, although without reaching the levels of controls. KD feeding did not affect the 5-HT transporter and receptors levels.

The feeding with KD improved brain BDNF levels in IBS rats and established negative feedback, leading to a compensatory downregulation of TrkB to maintain a physiological steady state. In addition, the present study found that KD does not significantly affect serotonin and BDNF systems in control rats, neither in colon nor in brain samples. Indeed, a positive role of ketosis in enhancing performance and cognition in the absence of underlying disorders appears to rely only on anecdotal evidence. A recent study showed that nutritional ketosis does not affect healthy individuals' cognitive function, sleep, or mood [51]. Furthermore, Brownlow et al. [52] have demonstrated that KD could affect metabolic parameters associated with energy metabolism but not hippocampal BDNF in control rats not subjected to stress.

The present paper offers an interesting picture in the colon and brain of the effect of early stress on some molecules involved in the communications between the two districts and the possible curative effect of the KD. Other than the fact that the state of ketosis and the ketonemia levels, which is very important especially in the management of pathologies with a neurological component, were not evaluated, another major drawback of this study is that possible variations have been investigated only at protein levels. So, the results reported herein are mandatory for further studies aiming to deeply analyze the complex pattern of the regulation of 5-HT and BDNF systems in order to shed light on the mechanisms leading to the stressed phenotype and the role of the dietary intervention. Although the current data were obtained in an animal model, which it can mimic the symptoms of IBS and therefore is useful for better identifying the molecular mechanisms of etiopathogenesis and potentially beneficial treatments [33], this does not faithfully reproduce what happens in humans. Undoubtedly, there is need to confirm these results in extensive clinical studies conducted on patients with IBS, also paying attention to the critical role of genetics as a possible modifier [47].

\section{Materials and Methods}

\subsection{Animals and Experimental Design}

The study was approved by the Italian Ministry of Health (approval date: 28 November 2018, n. 901/2018-PR) according to European Union guidelines (Directive 2010/63/E.U. for animal experiments).

The animals (Wistar rats) were housed at the animal facility of the National Institute of Gastroenterology "S. de Bellis" Research Hospital, Castellana Grotte, Bari, Italy. All the applied procedures followed the International Guidelines for using laboratory animals, minimizing animal suffering.

The IBS in adulthood was induced using the animal model of the newborn rats subjected to early-life stress through MD [33]. Postnatal Day 0 (PND 0) was considered as the birthday. Within the PNDs 2 to 14, the puppies experienced MD for $3 \mathrm{~h}$ a day.

After weaning, the animals subjected to MD were further divided into two subgroups, one group fed a standard diet (IBS-Std), and one group fed a low-carbohydrate, high-fat ketogenic diet (IBS-KD). The experimental design also included a control group of animals without MD and fed a standard diet (Ctrl-Std) and a group fed a low-carbohydrate, high-fat ketogenic diet (Ctrl-KD) (Table 1). Only male rats were considered for this study.

Diets (4RF21 standard diet and ketogenic diet) were purchased by Mucedola Srl, Settimo Milanese, Italy, and administered ad libitum for ten weeks after PND 14. Their composition is shown in Table 2. 
Table 1. Experimental groups: no irritable bowel syndrome (IBS) rats fed a standard diet (Ctrl-Std); no IBS rats fed a low-carbohydrate, high-fat ketogenic diet (Ctrl-KD); IBS rats fed a standard diet (IBS-Std); IBS rats fed a low-carbohydrate, high-fat ketogenic diet (IBS-KD). Maternal deprivation (3 hours/day from Postnatal Day (PND) 2 to 14). Treatment (for ten weeks after PND 14).

\begin{tabular}{cccc}
\hline Group & $\begin{array}{c}\text { Rats } \\
\text { (Number) }\end{array}$ & $\begin{array}{c}\text { Maternal Deprivation } \\
\text { (3 h/Day from PNDs 2 to 14) }\end{array}$ & $\begin{array}{c}\text { Treatment } \\
\text { (for Ten Weeks after PND 14) }\end{array}$ \\
\hline Ctrl-Std & 12 & No & Standard diet \\
Ctrl-KD & 13 & No & Ketogenic diet \\
IBS-Std & 11 & Yes & Standard diet \\
IBS-KD & 17 & Yes & Ketogenic diet \\
\hline
\end{tabular}

Table 2. Main constituents of Standard Diet and Ketogenic Diet.

\begin{tabular}{ccc}
\hline Analytical Constituents & Standard Diet & Ketogenic Diet \\
\hline Moisture & $12 \%$ & $0 \%$ \\
Crude protein & $18.5 \%$ & $16.0 \%$ \\
Crude oils and fats & $3.0 \%$ & $67.0 \%$ \\
Crude fibers & $6.0 \%$ & $6.0 \%$ \\
Crude ash & $7.0 \%$ & $4.5 \%$ \\
\hline
\end{tabular}

Rats were checked every day, evaluating different parameters regarding the degree of suffering and stress induced experimentally (blepharospasm, hollow cheeks, abnormal position of the ears and the whiskers, appetite loss, and liquid stools). Each parameter was recorded, attributing a score from 0 (absent) to 2 (evident) to calculate the possible onset of pain and suffering.

All animals in the study did not show any of the above stress-related symptoms, except for a slowdown in the growth of puppies with MD, which had lower weights than the control-group puppies.

After treatment, the animals were sacrificed by inhalation of an overdose of isoflurane, and both colon and brain samples were immediately removed and stored at $-80^{\circ} \mathrm{C}$ until assayed.

\subsection{Serotonin Levels}

The serotonin levels in colon and brain samples from all the experimental groups of rats were evaluated using the enzyme-linked immunosorbent assay (Elisa) kits (MyBioSource, San Diego, CA, USA), following the manufacturer's instructions.

\subsection{Western Immunoblotting}

Protein extracts were obtained using a standard procedure from colon and brain samples of Ctrl-Std, KD, IBS-Std, and IBS-KD rats. For Western blot analysis, the aliquots of $50 \mu \mathrm{g}$ of total protein extracts from each sample were loaded into $10 \%$ pre-cast polyacrylamide gels (Bio-Rad, Milan, Italy). Anti-5-HT $3 \mathrm{~B}$, anti-5-HT 4 , anti-SERT (Abcam, Cambridge, UK), anti-BDNF (MyBioSource, San Diego, CA, USA), anti-TrkB (Thermo Scientific, Rockford, IL, USA), anti- $\beta$-actin, and anti-GAPDH (Cell Signaling, Danvers, MA, USA) were used as primary antibodies. The proteins were detected by chemiluminescence (ECL, Bio-Rad, Milan, Italy), and the densitometric analysis of each protein-related signal was obtained using the Molecular Imager Chemidoc ${ }^{\mathrm{TM}}$ (Bio-Rad, Milan, Italy) and normalized against $\beta$-actin or GAPDH expression.

\subsection{Statistical Analysis}

Due to the non-normal distribution of the data, nonparametric tests were performed. Data were analyzed by Kruskal-Wallis analysis of variance and Dunn's Multiple Comparison Test. Differences were considered significant at $p<0.05$. All data represent the results of at least two independent experiments and are expressed as mean \pm SEM. A specific statistical package was used for the exact nonparametric inference (StataCorp 2005; Stata Statistical Software: Release 9, College Station, TX, USA). 


\section{Conclusions}

In conclusion, although partial, the results from this paper provide preliminary evidence of the efficacy of KD in improving imbalanced gut-brain interconnections, thereby reducing the damaging effects of stress in an animal model of IBS. This finding could have future clinical repercussions since the possibility of interrupting the dysfunction of the brain-gut axis through specific dietary treatments could allow new therapeutic strategies based on their neuroprotective properties.

Author Contributions: Conceptualization, A.O. and G.C.; methodology, G.C. and A.O.; resources, F.R.; data curation, A.O. and G.C.; writing original draft preparation, A.O., G.C. and F.R.; writing, review, and editing, A.O., G.C., M.N. and F.R.; visualization, F.R.; supervision, F.R. and A.O.; project administration, F.R.; funding acquisition, F.R. All authors have read and agreed to the published version of the manuscript.

Funding: This work was supported by RC 2020-2021, Prog. N$^{\circ} 26$ (DDG n. 2/2020) and Fondi di Ateneo 2017-18, Università di Bari.

Institutional Review Board Statement: The study was approved by the Italian Ministry of Health (approval date: 28 November 2018, n. 901/2018-PR) according to European Union guidelines (Directive 2010/63/EU for animal experiments). All the applied procedures followed the International Guidelines for the use of laboratory animals.

Informed Consent Statement: Not applicable.

Data Availability Statement: The data that support the findings of this study are available from the corresponding author upon reasonable request.

Acknowledgments: The authors thank Vito Spilotro for his excellent technical support.

Conflicts of Interest: The authors declare no conflict of interest.

\section{References}

1. Sperber, A.D.; Dumitrascu, D.; Fukudo, S.; Gerson, C.; Ghoshal, U.C.; Gwee, K.A.; Hungin, A.P.S.; Kang, J.Y.; Minhu, C.; Schmulson, M.; et al. The global prevalence of IBS in adults remains elusive due to the heterogeneity of studies: A Rome Foundation working team literature review. Gut 2017, 66, 1075-1082. [CrossRef]

2. Ladabaum, U.; Boyd, E.; Zhao, W.K.; Mannalithara, A.; Sharabidze, A.; Singh, G.; Chung, E.; Levin, T.R. Diagnosis, comorbidities, and management of irritable bowel syndrome in patients in a large health maintenance organization. Clin. Gastroenterol. Hepatol. 2012, 10, 37-45. [CrossRef]

3. Yu, Y.C.; Li, J.; Zhang, M.; Pan, J.C.; Yu, Y.; Zhang, J.B.; Zheng, L.; Si, J.M.; Xu, Y. Resveratrol Improves Brain-Gut Axis by Regulation of 5-HT-Dependent Signaling in the Rat Model of Irritable Bowel Syndrome. Front. Cell Neurosci. 2019, 13, 30. [CrossRef]

4. Ford, A.C.; Lacy, B.E.; Talley, N.J. Irritable Bowel Syndrome. N. Engl. J. Med. 2017, 376, 2566-2578. [CrossRef] [PubMed]

5. Grifka-Walk, H.M.; Jenkins, B.R.; Kominsky, D.J. Amino Acid Trp: The Far Out Impacts of Host and Commensal Tryptophan Metabolism. Front. Immunol. 2021, 12, 653208. [CrossRef] [PubMed]

6. Yu, K.B.; Hsiao, E.Y. Roles for the gut microbiota in regulating neuronal feeding circuits. J. Clin. Investig. 2021, 131, 131. [CrossRef] [PubMed]

7. Diwakarla, S.; Fothergill, L.J; Fakhry, J.; Callaghan, B.; Furness, J.B. Heterogeneity of enterochromaffin cells within the gastrointestinal tract. Neurogastroenterol. Motil. 2017, 29, e13101. [CrossRef] [PubMed]

8. Shajib, M.S.; Khan, W.I. The role of serotonin and its receptors in activation of immune responses and inflammation. Acta Physiol. 2015, 213, 561-574. [CrossRef] [PubMed]

9. Hansen, M.B.; Skadhauge, E. Signal transduction pathways for serotonin as an intestinal secretagogue. Comp. Biochem. Physiol. A Physiol. 1997, 118, 283-290. [CrossRef]

10. Stasi, C.; Bellini, M.; Bassotti, G.; Blandizzi, C.; Milani, S. Serotonin receptors and their role in the pathophysiology and therapy of irritable bowel syndrome. Tech. Coloproctol. 2014, 18, 613-621. [CrossRef] [PubMed]

11. Gershon, M.D. Review article: Roles played by 5-hydroxytryptamine in the physiology of the bowel. Aliment. Pharmacol. Ther. 1999, 13 (Suppl. S2), 15-30. [CrossRef]

12. Coleman, N.S.; Marciani, L.; Blackshaw, E.; Wright, J.; Parker, M.; Yano, T.; Yamazaki, S.; Chan, P.Q.; Wilde, K.; Gowland, P.A.; et al. Effect of a novel 5-HT3 receptor agonist MKC-733 on upper gastrointestinal motility in humans. Aliment. Pharmacol. Ther. 2003, 18, 1039-1048. [CrossRef]

13. Talley, N.J. Serotoninergic neuroenteric modulators. Lancet 2001, 358, 2061-2068. [CrossRef] 
14. Morita, H.; Mochiki, E.; Takahashi, N.; Kawamura, K.; Watanabe, A.; Sutou, T.; Ogawa, A.; Yanai, M.; Ogata, K.; Fujii, T.; et al. Effects of 5-HT2B, 5-HT3 and 5-HT4 receptor antagonists on gastrointestinal motor activity in dogs. World J. Gastroenterol. 2013, 19, 6604-6612. [CrossRef]

15. Vahora, I.S.; Tsouklidis, N.; Kumar, R.; Soni, R.; Khan, S. How Serotonin Level Fluctuation Affects the Effectiveness of Treatment in Irritable Bowel Syndrome. Cureus 2020, 12, e9871. [CrossRef]

16. Shao, Y.Y.; Guo, Y.T.; Gao, J.P.; Liu, J.J.; Chang, Z.P.; Feng, X.J.; Xu, D.; Deng, G.F.; Hou, R.G. Shaoyao-Gancao Decoction Relieves Visceral Hyperalgesia in TNBS-Induced Postinflammatory Irritable Bowel Syndrome via Inactivating Transient Receptor Potential Vanilloid Type 1 and Reducing Serotonin Synthesis. Evid. Based Complement. Altern. Med. 2020, 2020, 7830280. [CrossRef] [PubMed]

17. Wang, Y.; Dong, Y.; Wang, E.; Meng, Y.; Bi, Z.; Sun, S.; Zhang, C.; Fan, H.; Yuan, J. Shugan Decoction Alleviates Colonic Dysmotility in Female SERT-Knockout Rats by Decreasing M3 Receptor Expression. Front. Pharmacol. 2020, 11, 01082. [CrossRef] [PubMed]

18. Li, L.; Cui, H.; Li, T.; Qi, J.; Chen, H.; Gao, F.; Tian, X.; Mu, Y.; He, R.; Lv, S.; et al. Synergistic Effect of Berberine-Based Chinese Medicine Assembled Nanostructures on Diarrhea-Predominant Irritable Bowel Syndrome In Vivo. Front. Pharmacol. 2020, 11, 1210. [CrossRef]

19. Arevalo, J.C.; Wu, S.H. Neurotrophin signaling: Many exciting surprises! Cell Mol. Life Sci. 2006, 63, 1523-1537. [CrossRef] [PubMed]

20. Zheng, Z.; Zeng, Y.; Yang, W.; Wu, J. Irritable bowel syndrome may be induced by decreased neuroplasticity. Neuro Endocrinol. Lett. 2014, 35, 655-665. [PubMed]

21. Lommatzsch, M.; Braun, A.; Mannsfeldt, A.; Botchkarev, V.A.; Botchkareva, N.V.; Paus, R.; Fischer, A.; Lewin, G.R.; Renz, H Abundant production of brain-derived neurotrophic factor by adult visceral epithelia. Implications for paracrine and targetderived Neurotrophic functions. Am. J. Pathol. 1999, 155, 1183-1193. [CrossRef]

22. Liu, S. Neurotrophic factors in enteric physiology and pathophysiology. Neurogastroenterol. Motil. 2018, 30, e13446. [CrossRef] [PubMed]

23. Russo, F.; Chimienti, G.; Riezzo, G.; Linsalata, M.; D’Attoma, B.; Clemente, C.; Orlando, A. Adipose Tissue-Derived Biomarkers of Intestinal Barrier Functions for the Characterization of Diarrhoea-Predominant IBS. Dis. Mark. 2018, 2018, 1827937. [CrossRef] [PubMed]

24. Zhang, Y.; Qin, G.; Liu, D.R.; Wang, Y.; Yao, S.K. Increased expression of brain-derived neurotrophic factor is correlated with visceral hypersensitivity in patients with diarrhea-predominant irritable bowel syndrome. World J. Gastroenterol. 2019, 25, 269-281. [CrossRef]

25. Wang, P.; Du, C.; Chen, F.X.; Li, C.Q.; Yu, Y.B.; Han, T.; Akhtar, S.; Zuo, X.L.; Tan, X.D.; Li, Y.Q. BDNF contributes to IBS-like colonic hypersensitivity via activating the enteroglia-nerve unit. Sci. Rep. 2016, 6, 20320. [CrossRef]

26. Konturek, T.J.; Martinez, C.; Niesler, B.; van der Voort, I.; Monnikes, H.; Stengel, A.; Goebel-Stengel, M. The Role of Brain-Derived Neurotrophic Factor in Irritable Bowel Syndrome. Front. Psychiatry 2020, 11, 531385. [CrossRef]

27. Fan, F.; Tang, Y.; Dai, H.; Cao, Y.; Sun, P.; Chen, Y.; Chen, A.; Lin, C. Blockade of BDNF signalling attenuates chronic visceral hypersensitivity in an IBS-like rat model. Eur. J. Pain 2020, 24, 839-850. [CrossRef]

28. Yu, Z.C.; Cen, Y.X.; Wu, B.H.; Wei, C.; Xiong, F.; Li, D.F.; Liu, T.T.; Luo, M.H.; Guo, L.L.; Li, Y.X.; et al. Berberine prevents stress-induced gut inflammation and visceral hypersensitivity and reduces intestinal motility in rats. World J. Gastroenterol. 2019, 25, 3956-3971. [CrossRef]

29. Patel, N.V. "Let Food Be Thy Medicine": Diet and Supplements in Irritable Bowel Syndrome. Clin. Exp. Gastroenterol. 2021, 14, 377-384. [CrossRef]

30. Field, R.; Field, T.; Pourkazemi, F.; Rooney, K. Ketogenic diets and the nervous system: A scoping review of neurological outcomes from nutritional ketosis in animal studies. Nutr. Res. Rev. 2021, 1-14. [CrossRef]

31. Yarar-Fisher, C.; Li, J.; Womack, E.D.; Alharbi, A.; Seira, O.; Kolehmainen, K.L.; Plunet, W.T.; Alaeiilkhchi, N.; Tetzlaff, W. Ketogenic regimens for acute neurotraumatic events. Curr. Opin. Biotechnol. 2021, 70, 68-74. [CrossRef] [PubMed]

32. Olson, C.A.; Vuong, H.E.; Yano, J.M.; Liang, Q.Y.; Nusbaum, D.J.; Hsiao, E.Y. The Gut Microbiota Mediates the Anti-Seizure Effects of the Ketogenic Diet. Cell 2018, 173, 1728-1741. [CrossRef] [PubMed]

33. Vannucchi, M.G.; Evangelista, S. Experimental Models of Irritable Bowel Syndrome and the Role of the Enteric Neurotransmission J. Clin. Med. 2018, 7, 4. [CrossRef] [PubMed]

34. Reddel, S.; Putignani, L.; Del Chierico, F. The Impact of Low-FODMAPs, Gluten-Free, and Ketoenic Diets on Gut Microbiota Modulation in Pathological Conditions. Nutrients 2019, 11, 373. [CrossRef]

35. Gigante, I.; Tutino, V.; Russo, F.; De Nunzio, V.; Coletta, S.; Armentano, R.; Crovace, A.; Caruso, M.G.; Orlando, A.; Notarnicola, M. Cannabinoid Receptors Overexpression in a Rat Model of Irritable Bowel Syndrome (IBS) after Treatment with a Ketogenic Diet. Int. J. Mol. Sci. 2021, 22, 2880. [CrossRef]

36. Chimienti, G.; Orlando, A.; Lezza, A.M.S.; D'Attoma, B.; Notarnicola, M.; Gigante, I.; Pesce, V.; Russo, F. The Ketogenic Diet Reduces the Harmful Effects of Stress on Gut Mitochondrial Biogenesis in a Rat Model of Irritable Bowel Syndrome. Int. J. Mol. Sci. 2021, 22, 3498. [CrossRef]

37. Lutas, A.; Yellen, G. The ketogenic diet: Metabolic influences on brain excitability and epilepsy. Trends Neurosci. 2013, 36, 32-40. [CrossRef] 
38. Zilberter, T.; Zil-berter, Y. Ketogenic Ratio Determines Metabolic Effects of Macronutrients and Prevents Interpretive Bias. Front. Nutr. 2018, 5, 75. [CrossRef]

39. Camilleri, M.; Andrews, C.N.; Bharucha, A.E.; Carlson, P.J.; Ferber, I.; Stephens, D.; Smyrk, T.C.; Urrutia, R.; Aerssens, J.; Thielemans, L.; et al. Alterations in expression of p11 and SERT in mucosal biopsy specimens of patients with irritable bowel syndrome. Gastroenterology 2007, 132, 17-25. [CrossRef]

40. Xu, Z.; Zhang, M.; Dou, D.; Kang, T.; Li, F. Effects of Deoxyschisandrin on Visceral Sensitivity of Mice with Inflammatory Bowel Disease. Evid. Based Complement. Altern. Med. 2019, 2019, 2986097. [CrossRef]

41. Otani, K.; Okada, M.; Yamawaki, H. Diverse distribution of tyrosine receptor kinase B isoforms in rat multiple tissues. J. Vet. Med. Sci. 2017, 79, 1516-1523. [CrossRef]

42. Nibuya, M.; Takahashi, M.; Russell, D.S.; Duman, R.S. Repeated stress increases catalytic TrkB mRNA in rat hippocampus. Neurosci. Lett. 1999, 267, 81-84. [CrossRef]

43. Luukkonen, P.K.; Dufour, S.; Lyu, K.; Zhang, X.M.; Hakkarainen, A.; Lehtimäki, T.E.; Cline, G.W.; Petersen, K.F.; Shulman, G.I.; Yki-Järvinen, $\mathrm{H}$. Effect of a ketogenic diet on hepatic steatosis and hepatic mitochondrial metabolism in nonalcoholic fatty liver disease. Proc. Natl. Acad. Sci. USA 2020, 117, 7347-7354. [CrossRef]

44. Lane, J.; Brown, N.I.; Williams, S.; Plaisance, E.P.; Fontaine, K.R. Ketogenic Diet for Cancer: Critical Assessment and Research Recommendations. Nutrients 2021, 13, 3562. [CrossRef]

45. Operto, F.F.; Matricardi, S.; Pastorino, G.M.G.; Verrotti, A.; Coppola, G. The Ketogenic Diet for the Treatment of Mood Disorders in Comorbidity with Epilepsy in Children and Adolescents. Front. Pharmacol. 2020, 11, 578396. [CrossRef]

46. Araya, A.V.; Orellana, X.; Espinoza, J. Evaluation of the effect of caloric restriction on serum BDNF in overweight and obese subjects: Preliminary evidences. Endocrine 2008, 33, 300-304. [CrossRef]

47. Russo, F.; Chimienti, G.; Clemente, C.; Ferreri, C.; Orlando, A.; Riezzo, G. A possible role for ghrelin, leptin, brain-derived neurotrophic factor and docosahexaenoic acid in reducing the quality of life of coeliac disease patients following a gluten-free diet. Eur. J. Nutr. 2017, 56, 807-818. [CrossRef] [PubMed]

48. Gyorkos, A.; Baker, M.H.; Miutz, L.N.; Lown, D.A.; Jones, M.A.; Houghton-Rahrig, L.D. Carbohydrate-restricted Diet and Exercise Increase Brain-derived Neurotrophic Factor and Cognitive Function: A Randomized Crossover Trial. Cureus 2019, 11, e5604 [CrossRef]

49. Lim, S.Y.; Kwak, Y.S. Effect of nutrients and exhaustive exercise on brain function. J. Exerc. Rehabil. 2019, 15, 341-345. [CrossRef] [PubMed]

50. Seguella, L.; Pesce, M.; Capuano, R.; Casano, F.; Pesce, M.; Corpetti, C.; Vincenzi, M.; Maftei, D.; Lattanzi, R.; Del Re, A.; et al. High-fat diet impairs duodenal barrier function and elicits glia-dependent changes along the gut-brain axis that are required for anxiogenic and depressive-like behaviors. J. Neuroinflamm. 2021, 18, 115. [CrossRef] [PubMed]

51. Iacovides, S.; Goble, D.; Paterson, B.; Meiring, R.M. Three consecutive weeks of nutritional ketosis has no effect on cognitive function, sleep, and mood compared with a high-carbohydrate, low-fat diet in healthy individuals: A randomized, crossover, controlled trial. Am. J. Clin. Nutr. 2019, 110, 349-357. [CrossRef] [PubMed]

52. Brownlow, M.L.; Jung, S.H.; Moore, R.J.; Bechmann, N.; Jankord, R. Nutritional Ketosis Affects Metabolism and Behavior in Sprague-Dawley Rats in Both Control and Chronic Stress Environments. Front. Mol. Neurosci. 2017, 10, 129. [CrossRef] [PubMed] 